\title{
A complementary and alternative natural antidepressant therapy with emphasis on their mechanisms of action
}

\author{
Ali Esmail Al-Snafi * \\ Department of Pharmacology, College of Medicine, University of Thi qar, Iraq.
}

International Journal of Biological and Pharmaceutical Sciences Archive, 2021, 02(01), 007-021

Publication history: Received on 01 June 2021; revised on 04 July 2021; accepted on 08 July 2021

Article DOI: https://doi.org/10.53771/ijbpsa.2021.2.1.0056

\begin{abstract}
Medicinal plants can exert antidepressant activity by many mechanisms included neutralization of various stress mediators (regulate the activity of the hypothalamic- pituitary- adrenal axis and reduce CRF, and ACTH and corticosterone) [5], interaction with serotonergic systems (5-HT3, 5HT2A, 5-HT1A), noradrenergic ( $\alpha 1$ and $\alpha 2$ receptors) and dopaminergic (D1 and D2) receptors [6],restoring monoamine transmitters and their receptors to normal limits in certain regions of the cortex, in addition to reducing of oxidative stress and amelioration of inflammatory mediators. The current review discussed the antidepressant activity of medicinal plants, with emphasis on their mechanisms of action.
\end{abstract}

Keywords: Depression; Antidepressants; Medicinal plants; Herbal medicines

\section{Introduction}

Depression is a disease characterized by feelings of sadness and hopelessness, as well as the inability to experience pleasure in usual activities, changes in sleep patterns and appetite, loss of energy, and suicidal thoughts. Antidepressant drugs were classified according to their mode of action to monoamine oxidase inhibitors, tricyclic antidepressants, NA + 5-HT (serotonin) reuptake inhibitors, predominantly NA reuptake inhibitors, selective serotonin reuptake inhibitors and atypical antidepressants [1-4].Previous studies revealed that medicinal plants can possess antidepressant activity by many modes of action included: neutralization of various stress mediators (regulate the activity of the hypothalamicpituitary- adrenal axis and reduce CRF, and ACTH and corticosterone) [5], interaction with serotonergic systems (5HT3, 5HT2A, 5-HT1A), noradrenergic ( $\alpha 1$ and $\alpha 2$ receptors) and dopaminergic (D1 and D2) receptors [6],restoring monoamine transmitters and their receptors to normal limits in certain regions of the cortex, in addition to reducing of oxidative stress and amelioration of inflammatory mediators [7-9]. This review was designed to highlight the medicinal plants possessed antidepressant activity with emphasis on their mechanisms of action.

\section{Plants with antidepressant activity}

\subsection{Allium species}

The antidepressant effect of the quercetin-rich Allium cepa, was studied by using the rat behavioral model of depression [the forced swimming test (FST)]. Administration of onion powder $50 \mathrm{mg} / \mathrm{kg}$ daily for 14 days significantly reduced the immobility time in FST without changing the motor dysfunction, indicating antidepressant-like activity [10].

\footnotetext{
*Corresponding author: Ali Esmail Al-Snafi

Department of Pharmacology, College of Medicine, University of Thi qar,Iraq.

Copyright (C) 2021 Author(s) retain the copyright of this article. This article is published under the terms of the Creative Commons Attribution Liscense 4.0.
} 
The administration of aqueous extract of Allium macrostemon (100 or $200 \mathrm{mg} / \mathrm{kg}$, orally) significantly reduced the immobility duration in the forced swimming test and tail suspension test in mice $(\mathrm{P}<0.05)$.Administration of the extract (100 or $200 \mathrm{mg} / \mathrm{kg}$, orally, for 14 days) increased the number of 5-bromo-2-deoxyuridine (BrdU) bromodeoxy uridine assay-incorporating cells. The percentage of BrdU-incorporating cells co-localized with NeuN was significantly increased after administration of the extract $(100$ or $200 \mathrm{mg} / \mathrm{kg}, \mathrm{P}<0.05)$. The expression levels of brain-derived neurotrophic factor (BDNF) which is reported to be associated with neurogenesis were significantly increased in the hippocampus after administration of the extract [11].

Garlic extract 25, 50 and $100 \mathrm{mg} / \mathrm{kg}$ orally for 14 days in mice, significantly decreased immobility time in a dosedependent manner in both tail suspension test (TST) and forced swimming test (FST), indicating significant antidepressant-like activity comparable to fluoxetine $(20 \mathrm{mg} / \mathrm{kg}$ orally) and imipramine (15 mg/kg orally). The extract significantly decreased brain MAO-A and MAO-B levels, as compared to the control group [12-13].

\subsection{Aloysia gratissima}

The antidepressant-like and neuroprotective effects of Aloysia gratissima aqueous extract and the involvement of larginine-nitric oxide (NO)-cyclic guanosine monophosphate (cGMP) pathway. was evaluated through behavioral despair in FST and TST in mice. The immobility time in the FST and TST were reduced by the extract. The antidepressant-like effect of the extract in the TST was prevented by the pretreatment with N-methyl-d-aspartate (NMDA), l-arginine or sildenafil. The sub-effective dose of the extract produced a synergistic antidepressant-like effect with MK-801 (an antagonist of NMDA receptor), methylene blue, l-NNA (an inhibitor of NO synthase) or ODQ (an inhibitor of soluble guanylate cyclase) [14].

\subsection{Anethum graveolens}

The aqueous extract of Anethum graveolens $250 \mathrm{mg} / \mathrm{kg}$ orally, showed the best antidepressant effects than $1 \mathrm{~g} / \mathrm{kg}$ in rat by using FST in comparison with sertraline [15-16].

\subsection{Apium graveolens}

The anti-depressant effect of methanolic extract of Apium graveolens seeds (AGM) was investigated using two behavioral models in in-vivo study, the AGM $(100,200 \mathrm{mg} / \mathrm{kg})$ produced significant anti-depressant effect on mice and rats in both forced swim test and tail suspension test, its action was found to be similar to imipramine. The antidepressant effects of AGM were more prominent at $200 \mathrm{mg} / \mathrm{kg}$ when compared to lower dose of same fraction. The 3, n-butylphthalide and sedanenolide isolated from celery oil showed weak sedative activity, prolonged pentobarbital narcosis, and induced sleep immediately following recovery from a prior barbiturate treatment in mice [17-18].

\subsection{Apocynum venetum}

The antidepressant-like effect and monoaminergic mechanism of a flavonoids extract from Apocynum venetum leaves $(25,50$ and $100 \mathrm{mg} / \mathrm{kg}$, ig) were studied in mice using FST and TST. The monoamine neurotransmitters serotonin (5HT), noradrenaline (NA) and dopamine (DA) and their metabolites 5-hydroxyindole-3-acetic acid (5-HIAA), 3,4dihydroxyphenylacetic acid (DOPAC) and homovanillic acid (HVA) in the mouse hippocampus were also determined. The extract significantly reduced the immobility time in both the FST and TST. The extract also significantly increased the concentrations of the main neurotransmitters NE and DA along with their respective metabolites DOPAC, HVA in the hippocampus. The antidepressant-like effect of the extract was prevented by the pretreatment of mice with SCH23390 (a D1 receptor antagonist) or sulpiride (a D2 receptor antagonist) [19].

\subsection{Avena sativa}

The dried seeds and fresh plant exerted antidepressant activity, and it was useful where lowered mood is associated with anxiety and nervous exhaustion, especially during menopause. The fresh plant is a tonic remedy for all types of nervous debility, and can help to improve sleep duration and quality where the person is literally too tired to sleep. Oats also aid withdrawal from tobacco and drug addiction [20]. A dose of $1600 \mathrm{mg}$ of oat herb extract acutely improve attention and concentration and the ability to maintain task focus in older adults with differing levels of cognitive status [21-22].

\subsection{Bacopa monniera}

Bacosides A and B, bacopasides I and II and bacopasaponin C and the extract of Bacopa monniera exhibited antidepressant activity, while bacopaside VII did not have any antidepressant activity when tested on forced swimming and tail-suspension models in experimental animals [23-25]. 


\subsection{Benincasa hispida}

The antidepressant activity of the methanolic extract $(50,100$, and $200 \mathrm{mg} / \mathrm{kg}$, administered orally for 14 successive days) was tested in Swiss male albino mice in comparison with classical antidepressant drugs (imipramine $15 \mathrm{mg} / \mathrm{kg}$, fluoxetine $20 \mathrm{mg} / \mathrm{kg}$, and phenelzine $20 \mathrm{mg} / \mathrm{kg}$ ). The methanolic extract of B. hispida showed significant antidepressantlike activity in mice probably by inhibiting MAO-A, and through interaction with dopaminergic, $\alpha 1-$ adrenergic, serotoninergic, and GABA-ergic systems [26-27].

\subsection{Beta vulgaris}

The antidepressant effects of aqueous and methanolic extracts of Beta vulgaris 100200 and $400 \mathrm{mg} / \mathrm{kg} /$ day for 14 days, were studied using FST, TST and locomotor activity test (LAT) in mice. The extracts possessed significant antidepressant activity, especially, in mice given simultaneously combined doses of 200 or $400 \mathrm{mg} / \mathrm{kg} /$ day of methanolic extracts +10 $\mathrm{mg} / \mathrm{kg} /$ day fluoxetine, suggesting an additive serotonergic effect [28].

\subsection{Campsis grandiflora}

The antidepressant-like effect of ethyl acetate extract of the flowers of Campsis grandiflora in a mice model of chronic unpredictable mild stress (CUMS). The extract significantly reduced the depressant-like severity and immobility period as compared with untreated CUMS mice in FST and TST. In addition, the extract significantly elevated the contents of superoxide dismutase, glutathione peroxidase and decreased the contents of malonaldehyde (MDA) in mice brain [29].

\subsection{Chrysactinia mexicana}

The antidepressant-like effects of Chrysactinia mexicana were evaluated in the FST and TST in mice, the ambulatory activity was measure in the open field test (OFT), motor coordination was evaluated in the inverted screen and gyratory roller (IST and Rota-rod). Chrysactinia mexicana produced a significant reduction of the immobility time in both FST and TST, without affect the ambulatory activity of experimental mice [30].

\subsection{Citrus limon}

Anxiolytic and antidepressant effects and acute toxicity of ethanolic extract of the aerial parts of Citrus limon were studied in mice. Anxiolytic activity was evaluated using open field and elevated plus-maze tests. The antidepressant effect of the extract was studied by forced swimming test in mice. In the open field test, the oral route administration of the ethanolic extract alone showed significant sedative and antidepressant activities in mice $(p<0.05)$. The ethanolic extract did not alter motor coordination. The ethanolic extract, at three doses tested, showed antidepressant effect and produced decrease in immobility time. The authors concluded that the ethanolic extract of the aerial parts of $C$. limon have a sedative effect, which may be mediated by benzodiazepine-type receptors, and also an antidepressant effect, and the noradrenergic and serotoninergic mechanisms will probably play a role [31-32].

The sedative, anxiolytic and antidepressant effects of essential oil (EO) of leaves from Citrus limon were investigated in mice. The effects of EO were demonstrated by open-field, elevated-plus-maze, rota rod, pentobarbital-induced sleeping time, and forced swimming tests in mice. In the open-field test, EO at the doses of 50, 100 and $150 \mathrm{mg} / \mathrm{kg}$, after oral administration, significantly decreased the number of crossings, grooming, and rearing. In the elevated-plus-maze (EPM) test, EO increased the time of permanence and the number of entrances in the open arms. On the contrary, the time of permanence and the number of entrances in the closed arms were decreased. In the rota rod test, EO did not alter motor coordination and, thus, was devoid of effects, as related to controls. In the pentobarbital-induced sleeping time test, EO at the same doses significantly increased the animals sleeping time duration. Since EO, at the doses of 50, 100 and $150 \mathrm{mg} / \mathrm{kg}$, did not show a sedative effect in the open field test, these three doses when used in the forced swimming test, they were producing a decrease in the immobility time, similarly to that of imipramine (positive control). However, the antidepressant effects of EO were not altered by the previous administration of paroxetine. In addition, effects of EO in the forced swimming test were totally blocked by reserpine pretreatment [33].

The behavioral effects of Citrus limon juice were studied in rats at three different doses $(0.2,0.4$ and $0.6 \mathrm{ml} / \mathrm{kg})$, considered as low, moderate and high doses. Anxiolytic and antidepressant activities were specifically assessed twice during 15 days using open field test, elevated plus maze and forced swimming test. In open field test Citrus limon, revealed increase in distance travelled, number of central entries and amount of rearing's at moderate dose, while in the elevated plus maze, number of open arm entries were found to be increased. Whereas in forced swimming test, there was decrease in duration of immobility and increase in duration of climbing [34]. 


\subsection{Clitoria ternatea}

The effectiveness of Clitoria ternatea in the treatment of obsessive-compulsive was carried out experimentally. The influence of ethanolic extract of Clitorea ternateawas evaluated in marble-burying behavior in mice. The results revealed that ethanolic extract of Clitorea ternatea (EECT) $(100,200$ and $400 \mathrm{mg} / \mathrm{kg}$ ) reduced the marble burying behavior in mice. It was clear that EECT exhibited significant anti-compulsive effect in marble-burying behavior test in mice and the effect may be attributed to enhanced serotonergic function and might have influence on 5-HT reuptake [35-36].

A Perment polyherbal Ayurvedic formulation that contains equal parts of Clitoria ternatea, Withania somnifera Dun., Asparagus racemosus Linn., Bacopa monniera Linn., is used clinically as mood elevators. The behavioural effects and the possible mode of action of Perment was studied in stress induced depressive model. Chronic unpredictable mild stress (CUMS) was used to induce depression in rats. Open field exploratory behavior, elevated plus maze, social interaction and behavioural despair tests were used to assess behavior. Plasma noradrenaline, serotonin, corticosterone and brain/adrenal corticosterone levels were measured to support the behavioral effects of Perment. Exposure to CUMS for 21 days caused anxiety and depression in rats, as indicated by significant decrease in locomotor activity in the open field exploratory behaviour test and increased immobility period in the behavioural despair test. Perment predominantly exhibited antidepressant action than anxiolytic activity. Furthermore, Perment increased the plasma noradrenaline and serotonin levels in stressed rats. No significant alteration in the brain corticosterone level in stressed rats was observed with Perment treatment. However, the adrenal corticosterone level was decreased with Perment. It can be concluded that the Perment formulation exhibited synergistic activity, has a significant antidepressant and anxiolytic activity, which may be mediated through adrenergic and serotonergic system activation [37].

\subsection{Coriandrum sativum}

Diethyl ether extract of seeds of Coriandrum sativum showed more significant antidepressant effect than that of aqueous extract through interaction with adrenergic, dopamine-ergic and GABA-ergic system [38-39].

\subsection{Crocus sativus}

The antidepressant properties of stigmas and corms of Crocus sativus was studied experimentally. The aqueous ethanol extract of Crocus sativus corms was fractionated on the basis of polarity. Among the different fractions, the petroleum ether and dichloromethane fractions at doses of 150,300, and $600 \mathrm{mg} / \mathrm{kg}$ showed significant antidepressantlike activities in dose-dependent manners, by means of behavioral models of depression. The immobility time in the forced swimming test and tail suspending test was significantly reduced by the two fractions, without accompanying changes in ambulation when assessed in the open-field test. By means of a gas chromatography-mass spectrometry technique, twelve compounds of the petroleum ether fraction were identified. Aqueous stigmas extract also exerted antidepressive effects in the behavioral models. Crocin 1 and crocin 2 of the aqueous stigmas extract were identified by a reversed-phase HPLC analysis. The data indicated that antidepressant-like properties of aqueous stigma extracts attributed to crocin 1 [40-41].

The efficacy of hydroalcoholic extract of Crocus sativus (stigma) in comparison with fluoxetine in the treatment of mild to moderate depression was studiedin a 6-week double-blind, randomized trial. Forty adult outpatients who met the Diagnostic and Statistical Manual of Mental Disorders, fourth edition for major depression based on the structured clinical interview for DSM-IV and with mild to moderate depression were participated in the trial. Patients were randomly assigned to receive capsules of saffron $30 \mathrm{mg} /$ day (BD) (Group 1) and capsule of fluoxetine $20 \mathrm{mg} / \mathrm{day}$ (BD) (Group 2) for a 6-week study. Saffron at this dose was found to be effective similar to fluoxetine in the treatment of mild to moderate depression $(\mathrm{F}=0.13$, d.f. $=1, \mathrm{P}=0.71)$. There were no significant differences between the two groups in terms of observed side effects [42].

The efficacy of petal of Crocus sativus was compared with fluoxetine in the treatment of depressed outpatients in an 8week pilot double-blind randomized trial. Forty adult outpatients who met the DSM- IV criteria for major depression based on the structured clinical interview for DSM- IV were participated in the trial. Patients have a baseline Hamilton Rating Scale for Depression score of at least 18. In this double-blind and randomized trial, patients were randomly assigned to receive either capsule of petal of Crocus sativus $15 \mathrm{mg}$ bid (morning and evening) or fluoxetine $10 \mathrm{mg}$ bid (morning and evening) for an 8-week. At the end of trial, petal of Crocus sativus was found to be effective similar to fluoxetine in the treatment of mild to moderate depression $(F=0.03$, d.f. $=1, P=0.84)$. In addition, in the both treatments, 
the remission rate was $25 \%$. There were no significant differences in the two groups in terms of observed side effects [43].

The non-selective serotonin (5-HT) receptor agonist mCPP is known to induce obsessive-compulsive disorder (OCDlike) behavior (excessive self-grooming) in rodents and exacerbated symptoms in patients with OCD. Crocins (30 and $50 \mathrm{mg} / \mathrm{kg}$, ip) in rats attenuated mCPP-induced excessive self-grooming. The results also indicatedthat the effects of crocins on an animal model of OCD cannot be attributed to changes in locomotor activity, the effect could be attributed tointeraction between crocins and the serotonergic system [44].

In a randomized, double-blind study, $30 \mathrm{mg}$ of saffron extract (in capsules) given for 6 weeks resulted in significant alleviation of depression compared to placebo group, and no side effects were recorded. Many follow-ups double blind trials carried out on saffron preparation compared with imipramine and fluoxetine; showed that saffron possessed antidepressant effects [59, 45-47].

The molecular mechanism of antidepressant effect of aqueous extract of saffron and its effect on the levels of brainderived neurotrophic factor (BDNF), VGF neuropeptide, cyclic-AMP response element binding protein (CREB) and phospho-CREB (p-CREB) in rat hippocampus, were investigated. The aqueous extract of saffron (40, 80 and $160 \mathrm{mg} / \mathrm{kg} /$ day) and imipramine $10 \mathrm{mg} / \mathrm{kg} /$ day were injected intraperitoneally (ip) for 21 days to rats. The FST (forced

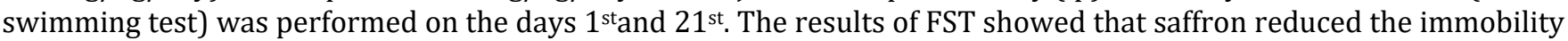
time. The protein levels of BDNF, CREB and p-CREB were significantly increased in saffron treated rats. VGF protein expression was also increased, but not significantly. The transcript levels of BDNF were also significantly increased. No significant changes in CREB and VGF transcript levels were observed. The authors concluded that aqueous extract of saffron has antidepressant effects and the mechanism of its antidepressant effect may be due to increasing the levels of BDNF, VGF, CREB and P-CREB in rat hippocampus [48].

\subsection{Cuscuta planiflora}

The effects of Cuscuta planiflora (500mg capsules) were evaluated in patients with major depression bya randomized triple-blind controlled clinical trial. Patients were taken the treatment for 8 weeks. Depression was measured before and after the study by Beck depression inventory and Hamilton depression inventory. There was a significant decrease in mean scores of Beck and Hamilton depression inventories in the group treated by Cuscuta planiflora(p<0.01) compared with control [49-50].

\subsection{Daucus carota}

The antidepressant potential of ethanol root extract of Dacus carota (DC)was studied in different animal models, FST, TST, apomorphine induced hypothermia (AIH), reserpine induced hypothermia (RIH), 5-HTP potentiation of head twitches (HTPPH) in mice. Fluoxetine $(25 \mathrm{mg} / \mathrm{kg}$ ) was used as a standard drug in FST, TST and HTPPH models and desipramine $(20 \mathrm{mg} / \mathrm{kg}$ ) was used as a standard drug in AIH and RIH models. The antidepressant activity of DC (400 $\mathrm{mg} / \mathrm{kg}$ ) was comparable to that of standard drugs [51-52].

\subsection{Eschscholtzia californica}

The aqueous-alcoholic extract from Eschscholtzia californica inhibited the enzymatic degradation of catecholamines as well as the synthesis of adrenaline. The extract also dramatically shortens the lag phase in the catalysis of phenolase probably due to their o-diphenol content, furthermore, dopamine beta-hydroxylase, monoamine oxidase (MAO-B) and diamine oxidases were inhibited by Eschscholtzia californica extracts. These mechanisms could explain theantidepressive and hypnotic activities of Eschscholtzia californic [53-54].

The protopine was also act as an inhibitor of both serotonin transporter and noradrenaline transporter in vitro assays. 5-hydroxy-DL-tryptophan(5-HTP)-induced head twitch response (HTR) and tail suspension test were adopted to study whether protopine has anti-depression effect in mice using reference antidepressant fluoxetine and desipramine as positive controls. In HTR test, protopine at doses of 5, 10, $20 \mathrm{mg} / \mathrm{kg}$ dose dependently increase the number of 5-HTPinduced HTR. Protopine at doses of $3.75 \mathrm{mg} / \mathrm{kg}, 7.5 \mathrm{mg} / \mathrm{kg}$ and $30 \mathrm{mg} / \mathrm{kg}$ also produces a dose-dependent reduction in immobility in the tail suspension test [55].

\subsection{Foeniculum vulgare}

The antidepressant effect of Vetiveria zizanioides and Foeniculum vulgare in comparison with antidepressant drug fluoxetine was investigated in depressive behavior in albino rats. Both Forced swimming testand Tail suspension test were used for screening antidepressant effect. The ethanolic extract of Vetiveria zizanioides (100mg/kg) and Foeniculum 
vulgare $(200 \mathrm{mg} / \mathrm{kg})$ together, fluoxetine $(10 \mathrm{mg} / \mathrm{kg})$ and saline were administered $30 \mathrm{mts}$ prior to the tests and the immobility period was recorded for $6 \mathrm{mts}$.The antidepressant effect of both were compared to that of fluoxetine. Vetiveria zizanioides $(100 \mathrm{mg} / \mathrm{kg})$ and Foeniculum vulgare $(200 \mathrm{mg} / \mathrm{kg})$ produced significant antidepressant effect by reduction in immobility period as compared to control. But as a group together they are equally effective as fluoxetine $(10 \mathrm{mg} / \mathrm{kg})[56-57]$.

The antidepressant effects of methanolic extract of Foeniculum vulgare fruits (MEFV) was investigated using force swim test in rats (FST), potentiation of norepinephrine (NE) toxicity in mice and haloperidol induce catalepsy (HIC) in mice. The extract of $F$. vulgare (250 and $500 \mathrm{mg} / \mathrm{kg}$ ) was administered orally to rats used in FST and $500 \mathrm{mg} / \mathrm{kg}$ was administered in HIC and same dose administered in NE toxicity in mice. The dose of $250 \mathrm{mg} / \mathrm{kg}$ and $500 \mathrm{mg} / \mathrm{kg}$ of extract significantly $(\mathrm{p}<0.001)$ reduced the immobility times in rats, $500 \mathrm{mg} / \mathrm{kg}$ showed more potent effect than imipramine $(30 \mathrm{mg} / \mathrm{kg})$.In NE toxicity model it was observed that MEFV does not interfere with adrenergic system. A significant $(\mathrm{P}<0.001)$ reduction in the duration of catalepsy was observed in the MEFV treated group and Fluoxetine group as compared to the haloperidol treated group. In HIC, mice were sacrificed on the seventh day and TBARS, glutathione, nitrite activities were estimated. Monoamine oxidase inhibiting effect and anti-oxidant effect of Foeniculum vulgare may be contributing favorably to the antidepressant-like activity [58].

\subsection{Glycyrrhiza glabra}

The effects of aqueous extract of Glycyrrhiza glabraon depression was investigated in mice using forced swim test (FST) and tail suspension test (TST). The extract of $G$. glabra $(75,150$, and $300 \mathrm{mg} / \mathrm{kg}$ ) was administered orally for 7 successive days in separate groups of male mice. The dose of $150 \mathrm{mg} / \mathrm{kg}$ of the extract significantly reduced the immobility times of mice in both FST and TST, without any significant effect on locomotor activity of mice. The efficacy of extract was found to be comparable to that of imipramine (15 mg/kg ip) and fluoxetine (20 mg/kg ip). Liquorice extract reversed reserpine-induced extension of immobility period of mice in FST and TST. Sulpiride (50 mg/kg ip, a selective $\mathrm{D}_{2}$ receptor antagonist $)$ and prazosin $\left(62.5 \mu \mathrm{g} / \mathrm{kg}\right.$ ip, an $\alpha_{1}$-adrenoceptor antagonist) significantly attenuated the extract-induced antidepressant-like effect in TST. On the other hand, $p$-chlorophenylalanine $(100 \mathrm{mg} / \mathrm{kg} \mathrm{ip}$, an inhibitor of serotonin synthesis) did not reverse antidepressant-like effect of liquorice extract. It seemed that the antidepressant-like effect of liquorice extract mediated by increase of brain norepinephrine and dopamine, but not by increase of serotonin [59-60].

\subsection{Gossypium species}

Aqueous extract of detoxified Gossypium herbaceum seeds showed antidepressant-like effect due to activation of adenyl cyclase-cAMP pathway in signal transduction system.Aqueous extract of detoxified Gossypium herbaceumseeds 0.01, $0.03,0.10,0.30 \mathrm{mg} / \mathrm{ml}$ was incubated directly with the synaptic membrane extracted from the cerebral cortex in rats, and adenylyl cyclase activity was detected by radio-immunoassay. Antidepressant and anxiolytic effects ofthe aqueous extract of detoxified Gossypium herbaceum seeds were caused by activation of AC-cAMP pathway in signal transduction system, thus protecting neurons from the lesion [61-63].

\subsection{Helianthus annuus}

The methanolic extract of Helianthus annuus seeds caused remarkable antidepressant activity (tail suspension test). $H$. annuus showed significant antidepressant activity $(\mathrm{p}<0.05)$ by decreasing the immobility time $($ H. annuus $100 \mathrm{mg} / \mathrm{kg}$, $93 \pm 0.47$; H. annuus $200 \mathrm{mg} / \mathrm{kg}, 78 \pm 1.3$ ) as compared with imipamine $(60 \mathrm{mg} / \mathrm{kg}, 30.2 \pm 0.64)$ and control (190.8 \pm 0.75$)$ [64-65].

\subsection{Hibiscus rosa-sinensis}

The anti-depressant activity of methanol extract containing anthocyanins (MHR) (30 and $100 \mathrm{mg} / \mathrm{kg}$ ) and anthocyanidins (AHR) (30 and $100 \mathrm{mg} / \mathrm{kg}$ ) of $\mathrm{H}$. rosa-sinensis flowers were evaluated in mice using behavioral tests (TST and FST). The mechanism of action involved in antidepressant activity was investigated by observing the effect of extract after pre-treatment with low dose haloperidol, prazosin and para-chlorophenylalanine (p-CPA). The results revealed that extract caused significant decrease in immobility time in TST and FST, similar to that of imipramine (10 $\mathrm{mg} / \mathrm{kg}$, ip) which served as a positive control. The extract significantly attenuated the duration of immobility induced by Haloperidol (50 $\mu \mathrm{g} / \mathrm{kg}$, ip., a classical D (2)-like dopamine receptor antagonist), Prazosin (62.5 $\mu \mathrm{g} / \mathrm{kg}$, ip, an $\alpha 1$ adrenoceptor antagonist) and p-chlorophenylalanine $(100 \mathrm{mg} / \mathrm{kg}, \mathrm{ip}, \times 3$ days; an inhibitor of serotonin synthesis $)$ in both TST and FST [66-67]. 


\subsection{Hyoscyamus niger}

The antidepressant effect of Hyoscyamus niger was evaluated in animal models [forced swim test (FST) and tail suspension test (TST) in mice] of depression with studying the possible mechanism underlyingthe antidepressant effect. Locomotor and anxiolytic activity were also studied. Hyoscyamus niger leaves ethanolic extract was administered to mice by oral route at dose of 25, 50, 100, 200 and $400 \mathrm{mg} / \mathrm{kg}$ for 14 days. Further an interaction of Hyoscyamus niger ethanolic extract with conventional antidepressant drugs were also studied at sub-effective doses. The ethanolic extract significantly reduced immobility duration of mice in FST and TST. The same doses did not change the motor activity in mice. However, high dose of extract showed anxiolytic activity. Interaction study with conventional antidepressant drugs reduced the duration of immobility count suggested, possible involvement of biogenic amine in antidepressant action [68-69].

\subsection{Hypericum perforatum}

With the using the rat forced swimming test, Hypericum perforatum extracts induced significant reduction of immobility. In other models, included acute and chronic forms of escape deficit induced by stressors, the extract protected rats from the consequences of unavoidable stress. The antidepressant effect of Hypericum perforatum extract could be attributed to its significant affinity for adenosine, GABA, $\mathrm{GABA}_{B}$ and glutamate receptors. The extract was also downregulated $\beta$ adrenergic receptors and upregulated serotonin $5-\mathrm{HT}_{2}$ receptors in the rat frontal cortex and causes changes in neurotransmitter concentrations in brain areas that are implicated in depression [70-71].

\subsection{Jasminum sambac}

The anxiolytic and antidepressant activities of ethanolic extract of Jasminum sambac flowers were evaluated using elevated plus maze, actophotometer, froced swim test and tail suspension test in mice. The ethanolic extracts of flowers of Jasminum sambac at a dose of 200 and $400 \mathrm{mg} / \mathrm{kg}$ ip, significantly possessed antidepressant and anxiolytic activity [72-73].

\subsection{Juglans regia}

The antidepressant effect of Juglans regia fruit extract (100 and $150 \mathrm{mg} / \mathrm{kg}$ ) was studied in animal models of depression (forced swimming test and tail suspension test). Both doses significantly decreased duration of immobility in both models of depression. The effect of extract was less significant than standard drug fluoxetine. The antidepressant activity could be attributed to the presence of omega 3 fatty acid in the extract [74-75].

\subsection{Lallemantia royleana}

The antidepressant effect of methanolic extract of Lallemantia royleana seeds $(25,50,75 \mathrm{mg} / \mathrm{kg}$, orally) was investigated in mice with acute mild stress model of depression using modified forced swimming test. All doses of the methanolic extract of Lallemantia royleana seeds produced significant reduction in \% immobility. However, the percentage of immobility time was significantly reduced at $50 \mathrm{mg} / \mathrm{kg}$, (56.67\%, p<0.01) [76-77].

\subsection{Matricaria chamomilla}

A randomized double-blind placebo-controlled trial was carried out to investigate the antidepressant effect of Matricaria chamomilla extract (1500 mg daily for 8 weeks) in subjects with generalized anxiety disorder with and without comorbid depression. Matricaria chamomilla produced clinically meaningful antidepressant effects in addition to its anxiolytic activity in subjects with generalized anxiety disorder and comorbid depression [78].

\subsection{Melissa officinalis}

The antidepressant-like activity of the aqueous extract (subchronic administration of 25, 75, 150, $300 \mathrm{mg} / \mathrm{kg}$ ) and essential oil (subchronic administration of 10,25, 75, 150,300 mg/kg) of the leaves of Melissa officinalis was studied in mice using in the forced swimming test. All doses of the aqueous extract, produced a significant reduction in immobility along with an increase in climbing behavior which was similar to that produced by imipramine. Essential oil caused a dose dependent reduction in immobility and an increase in climbing at all doses, compared to control group. Only the highest dose $(300 \mathrm{mg} / \mathrm{kg})$ of the essential oil showed a significant increase in swimming behavior. The aqueous extract, but not the essential oil, decreased spontaneous activity in a dose dependent manner [79].

The antidepressant-like activity of water extract of Melissa officinalis and rosmarinic acid were studied by evaluating its influence on the behaviors and the relevant neurotransmitters of rats performed to forced swimming test. In the acute 
model, extract of Melissa officinalis and rosmarinic acid significantly reduced depressive-like behavior. The effect of the extract administration on the reduction of immobility time

was associated with an increase in swimming time of the rats, indicating serotonergic neurotransmission modulation. Chromatographic analysis showed that the extract administration was associated with a reduction in the serotonin turnover rate [80].

The anxiolytic and antidepressant effects of Melissa officinalis tea were studied in burn patients. The serum levels of antioxidants were measured once before the intervention and at 20 days after the intervention. Depression, anxiety, and insomnia levels were measured by questionnaires. The percentages of those experiencing anxiety and depression were significantly less in Melissa officinalis treated patients than those in control group. Sleep quality in Melissa officinalis treated increased significantly. However, the mean serum antioxidant levels were not significantly changed by Melissa officinalis [81].

\subsection{Momordica charantia}

The methanolic extract (50-400 mg/kg, orally) was administered $1 \mathrm{~h}$ before behavioral studies using FST and TST to investigate antidepressantlike effect. The anxiolytic-like effect was evaluated using elevated plus maze test (EPM), holeboard test (HBT), and light-dark test (LDT). Acute treatment with the extract (50-400 mg/kg) significantly increased swimming time (86.51\%) and reduced the duration of immobility (52.35\%) in FST and TST with peak effects observed at $200 \mathrm{mg} / \mathrm{kg}$, respectively. The pretreatment of mice with either sulpiride (dopamine D2 receptor antagonist), metergoline (5-HT2 receptor antagonist), cyproheptadine (5-HT2 receptor antagonist), prazosin ( $\alpha 1$-adrenoceptor antagonist), yohimbine ( $\alpha 2$-adrenoceptor antagonist), and atropine (muscarinic cholinergic receptor antagonist) 15 min before oral administration of the extract $(200 \mathrm{mg} / \mathrm{kg})$ significantly blocked its anti-immobility effect. The methanolic extract of Momordica charantia $(200 \mathrm{mg} / \mathrm{kg})$ significantly reduced anxiety by increasing the open arm exploration (64.27\%) in EPM, number of head-dips in HBT (34.38\%), and time spent in light compartment (29.38\%) in the LDT. Pretreatment with flumazenil (GABAA receptor antagonist) $15 \mathrm{~min}$ before the extract $(200 \mathrm{mg} / \mathrm{kg}$ ) significantly blocked (54.76\%) its anxiolytic effect. The authors concluded that the the antidepressant-like effect of the extract involved the serotonergic (5-HT2 receptor), noradrenergic ( $\alpha 1$ - and $\alpha 2$ - adrenoceptors), dopaminergic (D2 receptor), and muscarinic cholinergic systems, while, the anxiolytic-like effect involved GABA- ergic mechanism [82].

\subsection{Morus alba}

The behavioral effects (depression, anxiety, climbing activity and thermal response) of an aqueous extract of Morus alba leaves tea were studied in mice. A significant antidepressant-like effect was detected in the animals receiving the extract at a dose of 100 or $200 \mathrm{mg} / \mathrm{kg}$. The effect of $200 \mathrm{mg} / \mathrm{kg}$ in decreasing the immobility time was comparable to $10 \mathrm{mg} / \mathrm{kg}$ desipramine [83].

\subsection{Morus nigra}

The acute and subchronic Morus nigra aqueous extract or syringic acid administration exerted antidepressant-like property in the behavioral testes in mice. The results suggested that the antidepressant-like effect of Morus nigra aqueous extract, at least in part, could be due to the syringic acid. Furthermore, the effect involved the nitro-oxidative system modulation in both the serum and brain of mice [84].

The antidepressant-like and neuroprotective effects of Morus nigra and syringic acid, were studied against glutamateinduced damage, the role of the PI3K/Akt/GSK-3 $\beta$ signaling pathway in antidepressant-like effects was also evaluated. Treatment with Morus nigra (3 mg/kg) and syringic acid ( $1 \mathrm{mg} / \mathrm{kg})$ for 7 days, triggered an antidepressant-like effect, similar to fluoxetine $(10 \mathrm{mg} / \mathrm{kg})$. The treatments evoked neuroprotection against glutamatergic excitotoxicity in hippocampal slices, and also afforded protection in cerebrocortical slices. The neuroprotective effect of Morus nigra and syringic acid was mediated, at least in part, by PI3K/Akt/GSK- $3 \beta$ signaling pathway [84-85].

The antidepressant-like effects, antioxidant effects, and neuroprotective effects of Morus nigra leaves extract and syringic acid were studied in mice model of depression induced by corticosterone. Corticosterone administered in male mice ( $20 \mathrm{mg} / \mathrm{kg}$, once a day, for 21 days) induced depressive-like phenotype, accompanied by increasing of oxidative stress markers (lipid peroxidation, nitrite, and protein carbonyl), decreasing of nonprotein thiols level, and impairment in the hippocampus. The treatment with Morus nigra leaves extract $(10 \mathrm{mg} / \mathrm{kg})$, syringic acid $(1 \mathrm{mg} / \mathrm{kg})$, or fluoxetine $(10 \mathrm{mg} / \mathrm{kg})$, once a day for the last 7 days of the corticosterone treatment, was able to abolish the behavioral alterations elicited by corticosterone. Both treatments also exerted antioxidant property in the mice's brain, reducing the amount of oxidative stress and abolishing the corticosterone-induced damage in the hippocampal slices. Furthermore, they 
protected the hippocampus against the damage induced by the association between corticosterone administration and glutamate excess [86].

\subsection{Newbouldia laevis}

The antidepressant activities of the hydroethanol leaf extract of Newbouldia laevis were evaluated in mice using FST and TST in mice. In the FST and TST, the extract $(25-200 \mathrm{mg} / \mathrm{kg})$ increased the latency and reduced the total duration of immobility $(\mathrm{p}<0.05)$. The effect of the extract on duration of immobility was significantly reversed by sulpiride (Dopamine $\mathrm{D}_{2}$ receptor antagonist) [87].

\subsection{Nigella sativa}

The antidepressant effect of Nigella sativa seed extracts of different germination phases was studied in experimental animals using forced swim test and tail suspension test. Nigella sativa extracts exhibited a slight reduction in the immobility of rats [88].

Hydroalcoholic extract of Nigella sativa and thymoquinone were investigated for their effect on lipopolysaccharide induced depression like behavior in rats using forced swimming test and open field test. The immobility time in lipopolysaccharide group was higher than that of saline control group, whereas, Nigella sativa extract or thymoquinone lowered immobility times compared with lipopolysaccharide group. In

the open- field test, the peripheral crossing number was higher in lipopolysaccharide group than saline control, while the animals pretreated with Nigella sativa extract or thymoquinone showed lower peripheral crossing number than lipopolysaccharide group. In addition, the central crossing number was lower in the lipopolysaccharide group than that of saline controls, whereas, in animals pretreated with Nigella sativa extract or thymoquinone, the central crossing number was higher than that of lipopolysaccharide group [89].

The antidepressant effect of the polar extract of Nigella sativa seeds and its sub-fractions was evaluated through the immobility duration in tail suspension and forced swim tests (FSTs) in mice. The polar extract and two of its subfractions were significantly decreased the immobility time of mice when subjected to both tail suspension and forced swim tests, the effects were comparable to standard drug (sertraline, $5 \mathrm{mg} / \mathrm{kg}$ ). The treatments did not affect the number of crossings and rearing in the open field test. Quercetin-3-O- $\alpha$-L-rhamnopyranoside 1, quercetin-7-0- $\beta-$ Dgluco- pyranoside 2, tauroside E 3, and sapindoside B were isolated as the potential antidepressant constituents [90].

The effect of Nigella sativa seeds on mood, anxiety and cognition in adolescent human males, was carried out at a boarding school in Bangladesh. Forty-eight healthy adolescent human males were divided into two groups: A and B The treatment procedure for group A and B were one capsule of $500 \mathrm{mg}$ placebo or $500 \mathrm{mg}$ Nigella sativa seeds respectively, once daily for four weeks. All the volunteers were assessed

for cognition with modified California verbal learning test-II (CVLT-II), mood with Bond-Lader scale and anxiety with state-trait anxiety inventory (STAI) at the beginning and after four weeks of either Nigella sativa or placebo ingestion [91].

\subsection{Ocimum basilicum}

The oil of Ocimum basilicum and fluoxetine were evaluated from immobility time and serotonin level in plasma in mice. By tail suspension test, there was significant difference after oil therapy $(P<0.001)$ and fluoxetine $(p=0.001)$. There was no dose suitability between sweet basil oil and fluoxetine based on tail suspension test $(\mathrm{P}<0.001)$. Serotonin level in plasma before and after therapy showed significant difference in all groups $(\mathrm{P}<0,001)$. There was no dose suitability between sweet basil oil and fluoxetine based on serotonin level in plasma $(\mathrm{P}<0,001)$. The antidepressant activity of sweet basil oil and fluoxetine was not similar based on immobility time and serotonin level in plasma [92-93].

\subsection{Panax ginseng and Polygala tenuifolia}

The impact of SY treatment (67.5, 135, or $270 / \mathrm{kg} /$ day, orally) (kai-xin-san formula of traditional Chinese medicine, consisted of the water extract of Panax ginseng and Polygala tenuifolia) was investigated in chronic unpredictable mild stress (CUMS)-induced depressive-like behaviors using TST, FST, novelty-suppressed feeding test (NSFT) and sucrose preference test (SPT). The results of SPT, NSFT, FST, and TST confirmed the antidepressant actions of SY. Additionally, SY treatment induced the BDNF signaling pathway and reversed the hippocampal neurogenesis caused by CUMS [94]. 


\subsection{Siphocampylus verticillatus}

The antidepressant-like effect of the hydroalcoholic extract of the aerial parts of Siphocampylus verticillatus, was investigated using FST and TST in mice. The immobility times in both FST and TST were significantly reduced by the extract (100-1000 mg/kg, ip).The oral administration of theextract was also effective in reducing the immobility time in the TST, comparable to that of imipramine $(15 \mathrm{mg} / \mathrm{kg}$, ip) and fluoxetine $(32 \mathrm{mg} / \mathrm{kg}$, ip.). The anti-immobility effect of the extract $(600 \mathrm{mg} / \mathrm{kg}$, ip.) was not affected by pre-treatment with naloxone ( a non-selective opioid receptor antagonist) or L-arginine ( a nitric oxide precursor). While, it was significantly reduced by pre-treatment of animals with p-chlorophenylalanine (an inhibitor of serotonin synthesis), sulpiride (a selective D2 receptor antagonist), prazosin (an $\alpha 1$ adrenoreceptor antagonist) or by guanosine 5 '-monophosphate (a nucleotide blocks some actions elicited by NMDA). The extract also inhibited in a graded manner the uptake of monoamines. It was more potent and more efficacious in inhibiting the synaptosomal uptake of noradrenaline and serotonin than dopamine [95].

\subsection{Taraxacum officinale}

The water extract of Taraxacum officinale leaves and roots $(50,100$ and $200 \mathrm{mg} / \mathrm{kg}$ ) were investigated in mice for antidepressant effect using FST, TST and open field test (OFT). CRF, ACTH and corticosterone concentrations were also determined. Chronic treatment (14-days) with the extract at the doses of 50, 100 and $200 \mathrm{mg} / \mathrm{kg}$ significantly decreased the immobility time in both FST and TST. Acute treatment (1-day) with the extract at a dose of $200 \mathrm{mg} / \mathrm{kg}$ also markedly decreased the immobility time in both FST and TST. All the treatments did not affect the locomotor activity in the OFT. FST induced significant increase in serum CRF, ACTH and corticosterone levels, while, 14 days treatmentwith the extract decreased the serum CRF and corticosterone levels by all doses [96].

\subsection{Trichilia monadelpha}

The antidepressant-like effect of extracts petroleum ether, ethyl acetate, and hydroethanolic extracts (30-300 $\mathrm{mg} / \mathrm{kg}$, orally) of the stem bark of Trichilia monadelphawas investigated using FST and TST. All the extracts significantly induced a decline in immobility in the FST and TST. The extracts showed increase in swimming and climbing in the FST as well as a significant enhancement in swinging and/or curling scores in the TST, suggesting a possible involvement of monoaminergic and/or opioidergic activity [97].

\subsection{Trigonella foenum graecum}

The antidepressant effect of ethanolic extract of seeds of Trigonella foenum graecum was investigated using FST, TST and monoamine (MAO) assay. The ethanolic extract of seeds of Trigonella foenum graecum showed antidepressant effect by both tests, it also inhibited the activity of MAO-A and B which represented the mechanism of antidepressant effect of Trigonella foenum graecum [98].

\section{Conclusion}

Growing evidence suggests that medicinal plants extracts may represent an alternative strategy for the treatment of depression. Further randomized and placebo-controlled trials are necessary to confirm the efficacy and safety of these plants as a possible remedy for this disorder.

\section{Compliance with ethical standards}

\section{Acknowledgments}

I acknowledged the dean of Thi qar college of medicine for scientific support.

\section{Disclosure of conflict of interest}

The authors confirm that this paper's content has no conflict of interests.

\section{References}

[1] Khushboo Sharma B.Antidepressants: mechanism of action, toxicity and possible amelioration. J Appl Biotechnol Bioeng. 2017;3(5):437-448.

[2] Al-Snafi AE. Therapeutic properties of medicinal plants: a review of medicinal plants with central nervous effects (part 1). Int J of Pharmacology \& Toxicology. 2015; 5(3): 177-192. 
[3] Al-Snafi AE. Medicinal plants with central nervous effects (part 2): plant based review. IOSR Journal of Pharmacy. 2016; 6(8): 52-75.

[4] Al-Snafi AE, Talab TA and Majid WJ. Medicinal plants with central nervous activity - An overview (Part 1). IOSR Journal of pharmacy 2019; 9(3): 52-102.

[5] Rai D, Bhatia G, Palit G, Pal R, Singh S, Singh HK. Adaptogenic effect of Bacopa monniera (Brahmi). Pharmacol Biochem Behav. 2003; 75(4): 823-30.

[6] Machado DG, Bettio LE, Cunha MP, et al. Antidepressant-like effect of rutin isolated from the ethanolic extract from Schinus molle L. in mice: evidence for the involvement of the serotonergic and noradrenergic systems. Eur J Pharmacol. 2008; 587(1-3): 163-8.

[7] Novío S, Núñez MJ, Amigo G, Freire-Garabal M. Effects of fluoxetine on the oxidative status of peripheral blood leucocytes of restraint-stressed mice. Basic Clin Pharmacol Toxicol. 2011; 109(5): 365-71.

[8] Szafrański T. Herbal remedies in depression-state of the art. Psychiatr Pol. 2014; 48(1): 59-73.

[9] Rai D, Bhatia G, Palit G, Pal R, Singh S, Singh HK. Adaptogenic effect of Bacopa monniera (Brahmi). Pharmacol Biochem Behav 2003; 75(4): 823-30.

[10] Sakakibara H, Yoshino S, Kawai Y, Terao J. Antidepressant-like effect of onion (Allium cepa L.) powder in a rat behavioral model of depression. Biosci Biotechnol Biochem. 2008;72(1):94-100.

[11] Lee S, Kim DH, Lee CH, Jung JW, Seo YT, Jang YP, Ryu JH. Antidepressant-like activity of the aqueous extract of Allium macrostemon in mice. J Ethnopharmacol. 2010;131(2):386-395.

[12] Dhingra D, Kumar V. Evidences for the involvement of monoaminergic and GABAergic systems in antidepressantlike activity of garlic extract in mice. Indian J Pharmacol. 2008;40(4):175-179.

[13] Al-Snafi AE. Pharmacological effects of Allium species grown in Iraq. An overview. International Journal of Pharmaceutical and health care Research.2013;1(4):132-147.

[14] Zeni AL, Zomkowski AD, Dal-Cim T, Maraschin M, Rodrigues AL, Tasca CI. Antidepressant-like and neuroprotective effects of Aloysia gratissima: investigation of involvement of L-arginine-nitric oxide-cyclic guanosine monophosphate pathway. J Ethnopharmacol. 2011;137(1):864-74.

[15] El Mansouri L, Bousta D, El Youbi-El Hamsas A, Boukhira S, Akdime H. Phytochemical screening, antidepressant and analgesic effects of aqueous extract of Anethum graveolens L. from southeast of Morocco. American Journal of Therapeutics. 2016;23(6): e1695-e1699.

[16] Al-Snafi AE. The pharmacological importance of Anethum graveolens- A review.International Journal of Pharmacy and Pharmaceutical Sciences. 2014; 6(4): 11-13.

[17] Srinivasa B, Desu R, Sivaramakrishna K. Antidepressant activity of methanolic extract of Apium graveolens seeds. IJRPC 2012;2(4): 1124-1127.

[18] Al-Snafi AE.The Pharmacology of Apium graveolens - A review. International Journal for Pharmaceutical Research Scholars. 2014; 3(1-1): 671-677.

[19] Zheng M, Fan Y, Shi D, Liu C. Antidepressant-like effect of flavonoids extracted from Apocynum venetum leaves on brain monoamine levels and dopaminergic system. J Ethnopharmacol. 2013;147(1):108-13.

[20] Boxall's Products containing Sceletium Tortuosum with Avena sativa. www. drboxalls.com.

[21] Berry NM, Robinson MJ, Bryan J, Buckley JD, Murphy KJ, Howe PRC. Acute effects of an Avena sativa herb extract on responses to the stroop color-word test. The Journal of Alternative and Complementary Medicine. 2011; 17(7): 635-637.

[22] Al-Snafi AE. The nutritional and therapeutic importance ofAvena sativa - An overview. InternationalJournalof Phytotherapy. 2015; 5(1): 48-56.

[23] Sairam K, Dorababu M, Goel RK, Bhattacharya SK. Antidepressant activity of standardized extract of Bacopa monniera in experimental models of depression in rats. Phytomedicine. 2002;9: 207-211.

[24] Zhou Y, Shen YH, Zhang C, Su J. Triterpene saponins from Bacopa monnieri and their antidepressant effects in two mice models. J Nat Prod. 2007; 70(4): 652-655.

[25] Al-Snafi AE.The pharmacology of Bacopa monniera. A review. International Journal of Pharma Sciences and Research. 2013; 4(12): 154-159. 
[26] Dhingra D, Joshi P. Antidepressant-like activity of Benincasa hispida fruits in mice: Possible involvement of monoaminergic and GABAergic systems. Journal of Pharmacology and Pharmacotherapeutics. 2012; 3(1): 60-61.

[27] Al-Snafi AE. The Pharmacological Importance of Benincasa hispida. A review.Int Journal of Pharma Sciences and Research. 2013; 4(12): 165-170.

[28] Invally M, Kaur G, Buttar HS. Evaluation of the antidepressant activity of Beta vulgaris alone and in combination with fluoxetine in mice.Journal of Pharmacology and Toxicology.2017;12: 33-41.

[29] Yu HC, Wu J, Zhang HX, Zhang HS, Qiao TT, Zhang JX, Zhang GL, Sui J, Li LW, Zhang LR, Lv LX. Antidepressant-like and anti-oxidative efficacy of Campsis grandiflora flower. J Pharm Pharmacol. 2015;67(12):1705-15.

[30] Cassani J, Ferreyra-Cruz OA, Dorantes-Barrón AM, Villaseñor RM, Arrieta-Baez D, Estrada-Reyes R. Antidepressant-like and toxicological effects of a standardized aqueous extract of Chrysactinia mexicana A. Gray (Asteraceae) in mice. J Ethnopharmacol. 2015;171:295-306.

[31] de Oliveira FR, Cerqueira Gs, de Freitas RLM,Júnior JSC, Feitosa CM, de Freitas RM.Anxiolytic-and antidepressantlike effects of the ethanolic extract from Citrus limon plant widely used in Northeastern Brazil. African Journal of Pharmacy and Pharmacology. 2013; 7(30): 2173-2179.

[32] Al-Snafi AE. Nutritional value and pharmacological importance of citrus species grown in Iraq. IOSR Journal of Pharmacy. 2016; 6(8): 76-108.

[33] Lopes C, Gonçalves eSá C, de Almeida AA, da Costa JP, Marques TH, Feitosa CM, Saldanha GB, de Freitas RM. Sedative, anxiolytic and antidepressant activities ofCitrus limon(Burn) essential oil in mice. Pharmazie. 2011;66(8):623-627.

[34] Khan RA, Riaz A. Behavioral effects of Citrus limon in rats. Metab Brain Dis.2015; 30(2):589-596.

[35] Shende V, Sahane R, Lawar M, Hamdulay N, Langote H.Evaluation of anti-compulsive effect of ethanolic extractin mice. Asian J Pharm Clin Res. 2012; 5(3):120-123.

[36] Al-Snafi AE.Pharmacological importance of Clitoria ternatea - A review. IOSR Journal of Pharmacy. 2016; 6(3): 68-83.

[37] Ramanathan M, Balaji B, Justin A. Behavioural and neurochemical evaluation of perment an herbal formulation in chronic unpredictable mild stress induced depressive model. Indian J Exp Biol. 2011;49(4):269-275.

[38] Sudha K, Deepak G, Sushant K, Vipul P,Nilofer N. Study of antidepressant like effect ofCoriandrum sativum and involvement of monoaminonergic and Gabanergic system. IJRAP. 2011; 2: 267-270.

[39] Al-Snafi AE. A review on chemical constituents and pharmacological activities of Coriandrum sativum. IOSR Journal of Pharmacy. 2016; 6(7): 17-42.

[40] Wang Y, Han T, Zhu Y, Zheng CJ, Ming QL, Rahman K, Qin LP. Antidepressant properties of bioactive fractions from the extract ofCrocus sativus L. J Nat Med. 2010; 64(1): 24-30.

[41] Al-Snafi AE.The pharmacology of Crocus sativus- A review. IOSR Journal of Pharmacy. 2016; 6(6): 8-38.

[42] Noorbala AA, Akhondzadeh S, Tahmacebi-Pour N, Jamshidi AH. Hydro-alcoholicextract ofCrocus sativus L. versus fluoxetine in the treatment of mild to moderatedepression: a double-blind, randomized pilot trial. J Ethnopharmacol.2005; 97(2):281-284.

[43] Basti AA, Moshiri E, Noorbala A, Jamshidi A, Abbasi SH, Akhondzadeh S.Comparison of petal of Crocus sativus L. and fluoxetine in the treatment of depressed outpatients: A pilot double-blind randomized trial. Progress in Neuro-Psychopharmacology \& Biological Psychiatry. 2007; 31: 439-442.

[44] Georgiadou G, Tarantilis PA, Pitsikas N. Effects of the active constituents ofCrocus sativus L., crocins, in an animal model of obsessive-compulsive disorder.Neurosci Lett. 2012; 528(1): 27-30.

[45] Akhondzadeh S, Tahmacebi-Pour N, Noorbala AA, Amini H, Fallah-Pour H, Jamshidi AH, Khani M. Crocus sativus L. in the treatment of mild to moderate depression: a double-blind, randomized and placebo controlled trial. Phytother Res. 2005; 19: 148 -151.

[46] Moshiri E, Basti AA, Noorbala AA, Jamshidi AH, Hesameddin Abbasi S, Akhondzadeh S. Crocus sativus L. (petal) in the treatment of mild-to-moderate depression: a double-blind, randomized and placebo controlled trial. Phytomedicine. 2006; 13: 607-611. 
[47] Akhondzadeh Basti A, Moshiri E, Noorbala AA, Jamshidi AH, Abbasi SH, Akhondzadeh S. Comparison of petal of Crocus sativus L. and fluoxetine in the treatment of depressed outpatients: a pilot double-blind randomized trial. Prog. Neuropsychopharmacol Biol Psychiatry. 2007; 31: 439 -442.

[48] Ghasemi T, Abnous K, Vahdati F, Mehri S, Razavi BM, Hosseinzadeh H. Antidepressant effect of Crocus sativus aqueous extract and its effect on CREB, BDNF, and VGF transcript and protein levels in rat hippocampus. Drug Res (Stuttg). 2015; 65(7): 337-343.

[49] Firoozabadi A,Zarshenas MM,Salehi A,Jahanbin S, Mohagheghzadeh A . Effectiveness ofCuscuta planiflora Ten. and Nepeta menthoides Boiss. \& Buhse in major depression: a triple-blind randomized controlled trial study. Journal of Evidence-Based Complementary \& Alternative Medicine. 2015; 20(2): 94-97.

[50] Al-Snafi AE. Traditional uses, constituents and pharmacological effects of Cuscuta planiflora. The Pharmaceutical and Chemical Journal. 2016; 3(4): 215-219.

[51] Babu PN, Nagaraju B, Yamini K, Dhananjaneyulu M, Venkateswarlu K,Mubina M. Evaluation of antidepressant activity of ethanolic extract of Dacus Carota in mice.J Pharm Sci \& Res. 2014; 6(2): 73-77.

[52] Al-Snafi AE. Nutritional and therapeutic importance ofDaucus carota- A review. IOSR Journal of Pharmacy. 2017; 7(2): 72-88.

[53] Kleber E, Schneider W, Schäfer HL, Elstner EF. Modulation of key reactions of the catecholamine metabolism by extracts from Eschscholtzia californica and Corydalis cava. Arzneimittelforschung. 1995;45(2):127-131.

[54] Al-Snafi AE. Eschscholzia californica: A phytochemical and pharmacological review.Indo Am J P Sci. 2017; 4(02): 257-263.

[55] Xu LF, Chu WJ, Qing XY, Li S, Wang XS, Qing GW, Fei J, Guo LH. Protopine inhibits serotonin transporter and noradrenaline transporter and has the antidepressant-like effect in mice models. Neuropharmacology. 2006;50(8):934-940.

[56] Glory Josephine I, Elizabeth AA, Punnagai K, Muthiah NS. Comparative study of Vetiveria zizanioides and Foeniculum vulgare extracts on behavioral despair of Wistar albino rats. Journal of Chemical and Pharmaceutical Research. 2015; 7(8):729-734.

[57] Al-Snafi AE.The chemical constituents and pharmacological effects of Foeniculum vulgare - A review.IOSR Journal ofPharmacy. 2018; 8(5):81-96.

[58] Singh JN, Sunil K,Rana AC. Antidepressant activity of methanolic extract of Foeniculum vulgare (fennel) fruits in experimental animal models. Journal of Applied Pharmaceutical Science. 2013; 3(9):65-70.

[59] Dhingra D, Sharma A. Antidepressant-like activity of Glycyrrhiza glabra L. in mouse models of immobility tests. Progress in Neuro-Psychopharmacology and Biological Psychiatry. 2006; 30(3): 449-454.

[60] Al-Snafi AE.Glycyrrhiza glabra: A phytochemical and pharmacological review. IOSR Journal of Pharmacy. 2018;8(6): 1-17.

[61] Dhamija HK, Parashar B, Singh J. Anti-depression potential of herbal drugs: An overview. J Chem Pharm Res. $2011 ; 3(5): 725-735$.

[62] Li YF, Yang M, Zhao YM, Luan XH, Luo ZP.Antagonistic effect of aqueous extract of detoxified cottonseeds on corticosterone-induced lesion in cultured PC12 cells. Zhongguo Zhong Yao Za Zhi. 2002;27(6):442-446.

[63] Al-Snafi AE.Chemical constituents and pharmacological activities ofGossypium herbaceum andGossypiumhirsutum - A review. IOSR Journal ofPharmacy. 2018; 8(5):64-80.

[64] Islam RT, Islam AT, Hossain MM, Mazumder K. Central nervous system activity of the methanol extracts of Helianthus annuus seeds in mice model.International Current Pharmaceutical Journal. 2015; 5(1): 1-4.

[65] Al-Snafi AE. The pharmacological effects of Helianthus annuus- A review. Indo Am J P Sc. 2018; 5(3):1745-1756.

[66] Shewale PB, Patil RA, Hiray YA. Antidepressant-like activity of anthocyanidins from Hibiscus rosasinensis flowers in tail suspension test and forced swim test. Indian J Pharmacol. 2012;44(4):454-457.

[67] Al-Snafi AE. Chemical constituents, pharmacological effects and therapeutic importance of Hibiscus rosa-sinensisA review.IOSR Journal of Pharmacy. 2018; 8(7): 101-119.

[68] Patil AD, Patil AY, Raje AA. Antidepressant like property of Hyoscyamus niger Linn. in mouse model of depression. Innovations in Pharmaceuticals and Pharmacotherapy. 2013;1(2): 60-69. 
[69] Al-Snafi AE.Therapeutic importance ofHyoscyamus species grown in Iraq (Hyoscyamus albus, HyoscyamusnigerandHyoscyamus reticulates)- A review.IOSR Journal ofPharmacy. 2018; 8(6):18-32.

[70] Gambarana C, Ghiglieri O, Tolu P, De Montis MG, Giachetti D, Bombardelli E, Tagliamonte A. Efficacy of an Hypericum perforatum (St. John's wort) extract in preventing and reverting a condition of escape deficit in rats. Neuropsychopharmacology. 1999;21(2):247-257.

[71] Al-Snafi AE. Encyclopedia of chemical constituents and pharmacological effects of Iraqi medicinal plants. Rigi Publication, India. 2015.

[72] Rambabu B, Patnaik KR. Anxiolytic and antidepressant activities of ethanolic extracts of Jasminum sambac, Chamomilla capitula, Lilium candidum, Sorghum helpense flowers. International Journal of Advances in Pharmaceutical Sciences. 2016; 7(3): 3108-3114.

[73] Al-Snafi AE. Pharmacological and therapeutic effects of Jasminum sambac - A review. Indo Am J P Sc. 2018; 5(3): 1766-1778.

[74] Rath BP, Pradhan D. Antidepressant activity of Juglans regia L. fruit extract. Int J Toxicol Pharmacol Res. 2009; 1 : 24-26.

[75] Al-SnafiAE.Chemical constituents, nutritional, pharmacological and therapeutic importance of Juglans regia - A review. IOSR Journal of Pharmacy.2018; 8(11): 1-21.

[76] Hyder N, Naqvi BS, Ishaq H, Usman S, Naqvi AA, Naveed S. Effect of Lallemantia royleana seeds Benth (Lamiaceae) seeds using acute mild stress model in NMRI male mice of depression. J Biotech and Biosafety. 2016; 4(2): 378382.

[77] Al-Snafi AE. Pharmacological and therapeutic effects of Lallemantia royleana-A review. IOSR Journal ofPharmacy. 2019; 9(6):43-50.

[78] Amsterdam JD, Li QS, Xie SX, Mao JJ. Putative antidepressant effect of chamomile (Matricaria chamomilla L) oral extract in subjects with comorbid generalized anxiety disorder and depression. J Altern Complement Med. 2019.

[79] Emamghoreishi M. Antidepressant effect of Melissa officinalis in the forced swimming test. DARU Journal of Pharmaceutical Sciences. 2009; 17(1): 42-47.

[80] Lin SH, Chou ML, Chen WC, et al. A medicinal herb, Melissa officinalis L. ameliorates depressive-like behavior of rats in the forced swimming test via regulating the serotonergic neurotransmitter. J Ethnopharmacol. 2015; 175: 266-272.

[81] Chehroudi S, Fatemi MJ, Isfeedvajani MS, et al. Effects of Melissa officinalis L. on reducing stress, alleviating anxiety disorders, depression, and insomnia, and increasing total antioxidants in burn patients. Trauma Mon. 2016; 22(4): e33630.

[82] Ishola IO, Akinyede AA, Sholarin AM. Antidepressant and anxiolytic properties of the methanolic extract of Momordica charantia Linn (Cucurbitaceae) and its mechanism of action. Drug Res (Stuttg). 2014; 64(7): 368-376.

[83] Sattayasai J, Tiamkao S, Puapairoj P. Biphasic effects of Morus alba leaves green tea extract on mice in chronic forced swimming model. Phytother Res. 2008; 22(4): 487-492.

[84] Dalmagro AP, Camargo A, Zeni ALB. Morus nigra and its major phenolic, syringic acid, have antidepressant-like and neuroprotective effects in mice. Metabolic Brain Disease. 2017; 32(6):1963-1973.

[85] Dalmagro AP, Camargo A, Rodrigue ALS, Zeni ALB. Involvement of PI3K/Akt/GSK-3ß signaling pathway in the antidepressant-like and neuroprotective effects of Morus nigra and its major phenolic, syringic acid. ChemicoBiological Interactions. 2019.

[86] Dalmagro AP, Camargo A, Pedron NB, Garcia SAM, Zeni ALB. Morus nigra leaves extract revokes the depressivelike behavior, oxidative stress, and hippocampal damage induced by corticosterone: a pivotal role of the phenolic syringic acid. Behav Pharmacol. 2020.

[87] Murtala AA, Akindele AJ. Anxiolytic- and antidepressant-like activities of hydroethanol leaf extract of Newbouldia laevis (P. Beauv.) Seem. (Bignoniaceae) in mice. J Ethnopharmacol. 2020;249:112420.

[88] Islam MH, Ahmad IZ, Salman MT. Neuroprotective effects of Nigella sativa extracts during germination on central nervous system. Pharmacogn Mag. 2015; 11(Suppl 1): S182-189. 
[89] Hosseini M, Zakeri S, Khoshdast S, Yousefian FT, Rastegar M, et al. The effects of Nigella sativa hydro-alcoholic extract and thymoquinone on lipopolysaccharide - induced depression like behavior in rats. J Pharm Bioallied Sci. 2012; 4: 219-225.

[90] Alorainy MS, El-Ashmawy IM, Fat'hi S. Potential antidepressant constituents of Nigella sativa seeds. Pharmacogn Mag. 2016; 12(Suppl 1): S27-31.

[91] Bin Sayeed MS, Shams T, Fahim Hossain S, Rahman MR, Mostofa A, et al. Nigella sativa L. seeds modulate mood, anxiety and cognition in healthy adolescent males. J Ethnopharmacol. 2014;152: 156-162.

[92] Suryani PR, Zulissetiana EF, Prananjaya BA. Antidepressant activity of basil leaves essential oil (Ocimum basilicum) in male balb/c mice. Journal of Physics. 2019; Conf. Series 1246:1-7.

[93] Al-Snafi AE. Chemical constituents and pharmacological effects of Ocimum basilicum- A review. International Journal of Pharmaceutical Research. 2021; 13(2): 2997-3013.

[94] Jiang N, Wang H, Li C, Zeng G, Lv J, Wang Q, Chen Y, Liu X. The antidepressant-like effects of the water extract of Panax ginseng and Polygala tenuifolia are mediated via the BDNF-TrkB signaling pathway and neurogenesis in the hippocampus. J Ethnopharmacol. 2021;267:113625.

[95] Rodrigues AL, da Silva GL, Mateussi AS, Fernandes ES, Miguel OG, Yunes RA, Calixto JB, Santos AR. Involvement of monoaminergic system in the antidepressant-like effect of the hydroalcoholic extract of Siphocampylus verticillatus. Life Sci. 2002;70(12):1347-58.

[96] Li YC, Shen JD, Li YY, Huang Q. Antidepressant effects of the water extract from Taraxacum officinale leaves and roots in mice. Pharm Biol. 2014;52(8):1028-32.

[97] Kukuia KKE, Mensah JA, Amoateng P, Amponsah SK, N'Guessan BB, Asiedu-Gyekye IJ. Antidepressant potentials of components from Trichilia monadelpha (Thonn.) J.J. de Wilde in Murine Models. Evid Based Complement Alternat Med. 2018;2018:6863973.

[98] Khursheed R, Rizwani GH, Sultana V, Ahmed M, Kamil A. Antidepressant effect and categorization of inhibitory activity of monoamine oxidase type A and B of ethanolic extract of seeds of Trigonella foenum graecum Linn. Pak J Pharm Sci. 2014;27(5 Spec no):1419-25. 